\title{
Effect of Oral Zinc Sulfate on Local Inflammatory Cytokines Level in Iraqi Women Infected With Human Papillomavirus (HPV)
}

\author{
Hula Y. Fadhil ${ }^{* 1}$, Iman M. Aufi ${ }^{2}$, Rana S.Aboud ${ }^{1}$, Faiza L. Tuma ${ }^{2}$ \\ ${ }^{l}$ Department of Biology, College of Science, University of Baghdad, Baghdad, Iraq \\ ${ }^{2}$ Departmentof Virology, the National Central Public Health Laboratory (NPL), Ministry of Health, Baghdad-
} Al-Andalus Street, Iraq

\begin{abstract}
This study was aimed to monitor oral zinc sulfate role on local cervical proinflammatory cytokines in $H P V$-infected women comparing with these cytokines before treatment application. A cervical secretion got from 28 infected women before and after treatment with zinc sulfate, these samples assessed various markers of inflammation including interleukin-1 $\beta, I L-8$, and IL-12. Results manifested that improve and clear the cervical HPV infections after three months of zinc treatment $46.43 \%$ and $21.43 \%$, respectively. Viral infections with single and multiple HPV high-risk types are raising of studied cytokines after 3-month compared with single HPV low-risk type. Moreover, this increasing was statistically significant only in IL-12 and IL-1. Women more than 30 years and with multiple HPV genotypes are the most benefit of zinc treatment had a high level of cytokines. This study concludes that IL-1 and IL-12 secretion are the most effects with zinc treatment at over three months to improve mild HPV infection with good hygiene.
\end{abstract}

Keywords: Human papillomavirus, Zinc sulfate, Cytokines, Cervical lesion and Iraqi women.

\section{Introduction}

The life cycle of HPV is characterized non-lytic, no viremia and free virus particles which shedding from mucosal surfaces with poor exposure to APC. Furthermore, the immune system unable to distinguish the infected virus and therefore does not stimulate any pro-inflammatory cytokines that trigger the dendritic cells and induce migration into the local environment [1]. On the other hand, expression of IL-8 during the HPV infections is down-regulated when viral early protein E6 and E7 are expressed [2]. Moreover, women with abnormal pap smears or cervical neoplasia have a lower systemic IL-12 level which suggests that HPV disease occurs with a relative decrease in Th1 cytokines and with a relative increase of Th2 cytokines [3]. Zinc is crucial to the normal development of immune cells, and it plays an important role in maintaining the activity of a range of immune cells, including neutrophils, monocytes, macrophages, natural killer cells, and B and T cells $[4,5]$. Thus, zinc deficiency in humans may be associated with an imbalance of Th1 and Th2 cells, reduced serum thymulin activity, employment of $\mathrm{T}$ naive cells, $\mathrm{T}$ cytolytic cells, and NK cell lytic activity [6]. In a study by Raza and Khan, who reported that patients having viral warts had serum zinc levels below the normal range which clearly indicates that although a considerable proportion of our population is deficient in zinc, this deficiency is present in a higher number of patients with persistent, progressive or recurrent viral warts [7]. Hence, this study was aimed to monitor oral zinc sulfate role on local cervical proinflammatory cytokines in HPV-infected women comparing with these cytokines before treatment application.

\subsection{Study design}

\section{Materials and Methods}

Our selection of patients for this study was based on containing them of HPV DNA and the grade of cervical intraepithelial neoplasia (Pap smear). Previously, detection of HPV DNA was performed on cervical cell samples using the real-time PCR and HPV Genoarray techniques and the last it is capable of amplifying 21 HPV genotypes, according to the manufacturer's protocol (Hybribio Limited Corporation, Hong Kong) [8, 9]. Furthermore, the cervical cells were examined with Pap smear in Al-Alawi hospital. A total of 28 cervical secretions were collected from women aged 20-55 years (31.54 \pm 6.85$)$. The infected women distributed to 11 women had single high-risk HPV, 9 had single low-risk and 8 infected with multiple HPV genotypes.

\subsection{Sample Collection}

A sample got from infected women at early of study and after one and three months of treatment with zinc sulfate $(220 \mathrm{mg} / \mathrm{daily})$. These specimens obtained with the cotton swabs following speculum insertion and before all other cervical samples were collected [10]. Two swabs were placed in the cervical secretion without touch the vaginal wall and vulva, remained to collect secretion for $1 \mathrm{~min}$, rinsed into sterile microfuge tubes containing $500 \mu \mathrm{l}$ PBS buffer and it stored at $-20 \mathrm{c} \dot{\circ}$ until use for ELISA test.

\begin{tabular}{|c|c|}
\hline DOI: $10.9790 / 3008-1203011417$ & www.iosrjournals.org \\
\hline
\end{tabular}


Effect of Oral zinc sulfate on local inflammatory cytokines level in Iraqi women infected with ..

\subsection{ELISA Test}

We assessed various markers of inflammation including interleukin-12 p70 (associated with Th1 protective responses), IL-1 $\beta$ (associated with leukocyte recruitment, activation of $\mathrm{NF}_{\mathrm{k}} \mathrm{B}$ and upstream induction of other cytokines prostanoids and nitric oxide associated with inflammation), IL-8 (associated with neutrophil recruitment), using specific ELISA kit (Biosource, Belgium).

\subsection{Statistical Analysis}

The data and graphs were carried out using SPSS program version 20 IBM. To eliminate the interleukin values at the early study, we applied the covariance analysis for measuring the impact of oral zinc therapy on the elevation of interleukin levels at viral infection site and their association with ages and infection type. Moreover, the role period of treatment, the correlation between interleukins and regression of infection were checked by using person coefficient and Chi-square test. Values were considered statistically significant $\mathrm{P} \leq 0.05$.

\section{Results and discussion}

Results of oral zinc sulfate treatment after three months manifested that improve and clear the cervical HPV infections in $46.43 \%$ and $21.43 \%$, respectively (Fig. 1). Hence, this treatment has a significant impact on HPV genital infection after three months $(X=6.73, \mathrm{P}<0.05)$.

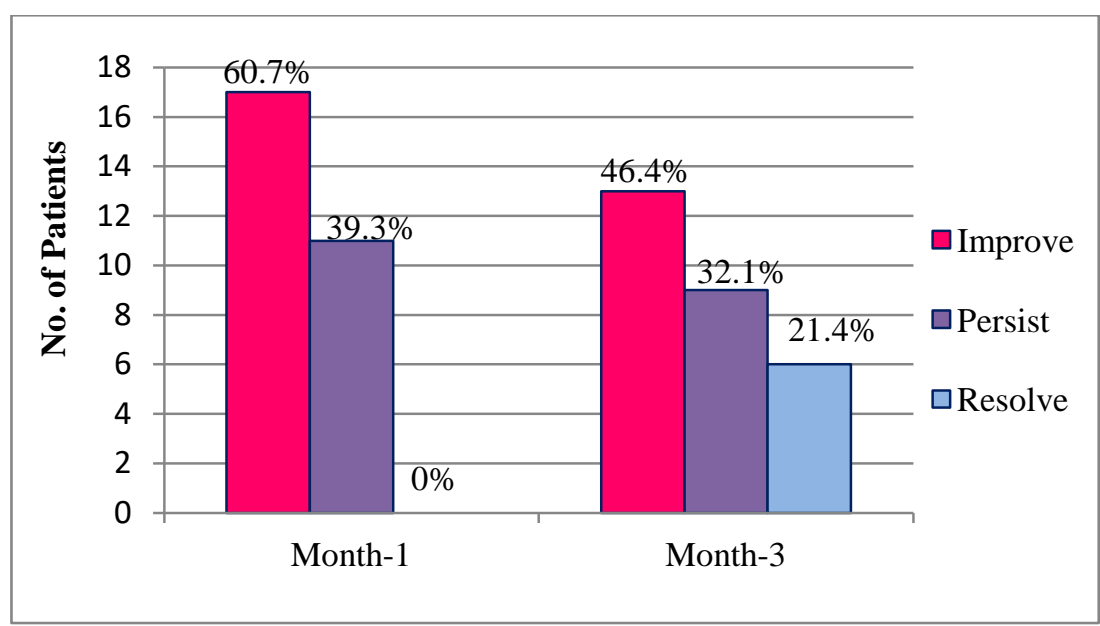

Figure 1. Consequence of zinc treatment after one and three months for HPV cervical and genital infection

In studies have shown HPV often insert itself on chromosome 10 when there is a disruption in zinc finger transcription factors [11]. High plasma zinc levels provide a protective effect against HPV-16, a strain of HPV strongly associated with cervical cancer [12]. Moreover, the effect of zinc on the common cold may be due to the increased zinc concentrations in the nasal mucosa, which may alter the conformation of the binding site between the virus and ICAM-1 [13]. Al-Gurari, et al. [14], used oral zinc sulfate for a total period of two months in the treatment of viral warts with a cure rate of $87 \%$. Also, other study showed that patients who received oral zinc sulfate, $60.97 \%$ showed a complete response at the end of six weeks in comparison to $6.45 \%$ partial response in the placebo group [15].

Regarding the age of HPV-infected women, the results pointed out that women more than 30 years old had the best response to treatment to raise of IL-1, IL-8, and IL-12 levels, but there are not statistically significant differences between age groups $(\mathrm{P}>0.05)$ (Fig. 2a,b,c). 
Effect of Oral zinc sulfate on local inflammatory cytokines level in Iraqi women infected with ..
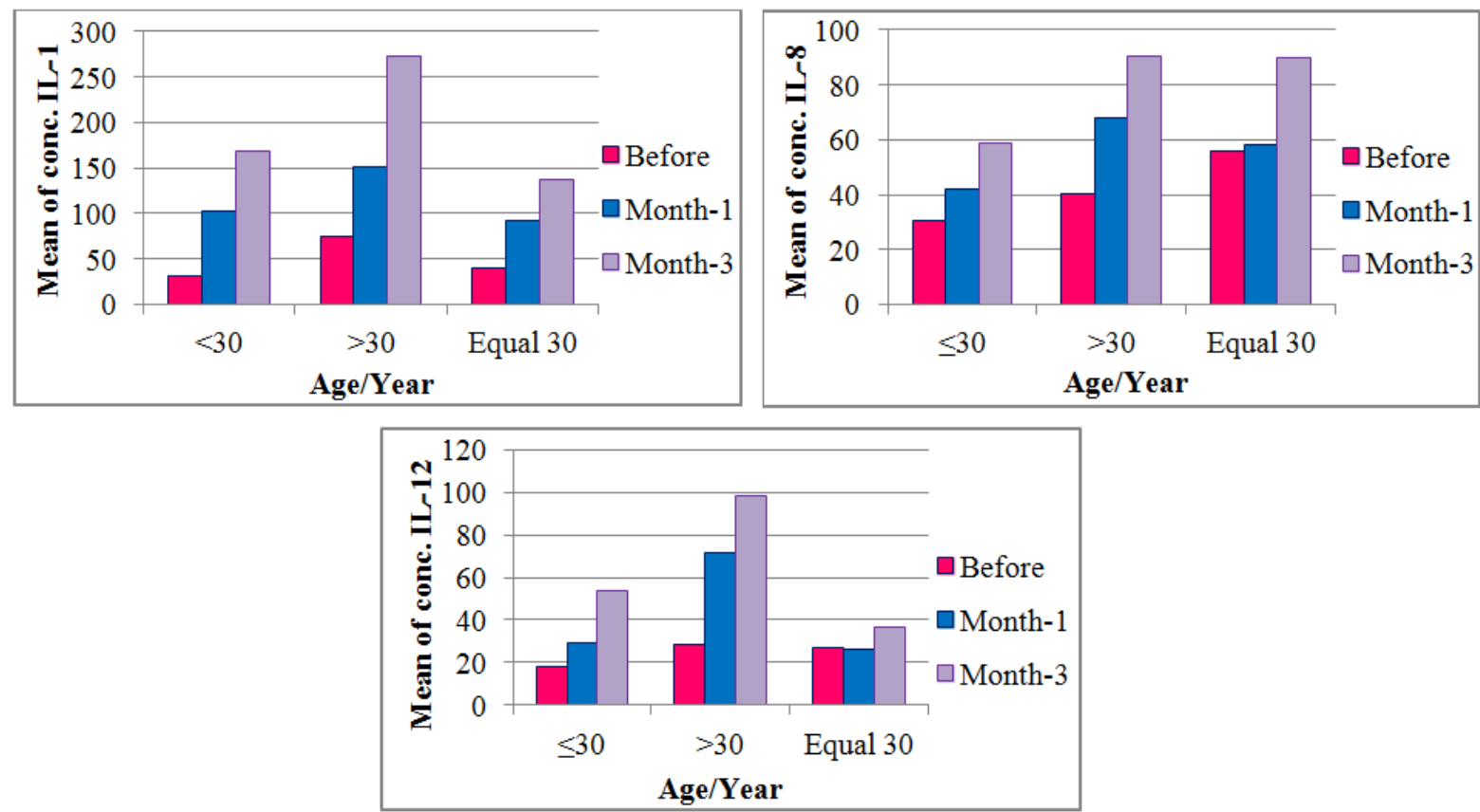

Figure 2. Observation of age groups with different cytokine levels in HPV infect women after on and three months of treatment with oral zinc sulfate, (a) for IL-1; (b) for IL-8 and (c) IL-12 level.

Increasing of plasma zinc improves an elderly person's resistance to infections, thereby increasing his or her immunity. Adequate zinc supplementation administered to vulnerable individuals could prevent the impairment of the immune system and substantially improve the host's resistance to infections in these populations [16]. Younger women were possibly exposed to HPV while they were immunologically naïve to HPV and could be explained by a possible defective cell-mediated immunity against HPV-induced [17]. Several studies suggested that the deficiency of the immune response could be associated with the expression of a particular HLA haplotype [18]. Figure 3a, b, and c demonstrate that HPV infections with single high risk and multiple are rising of studied immune markers after 3-month compared with single low risk. Meanwhile, this increasing was statistically significant only in IL-12 and IL-1 $(\mathrm{P}<0.05)$.
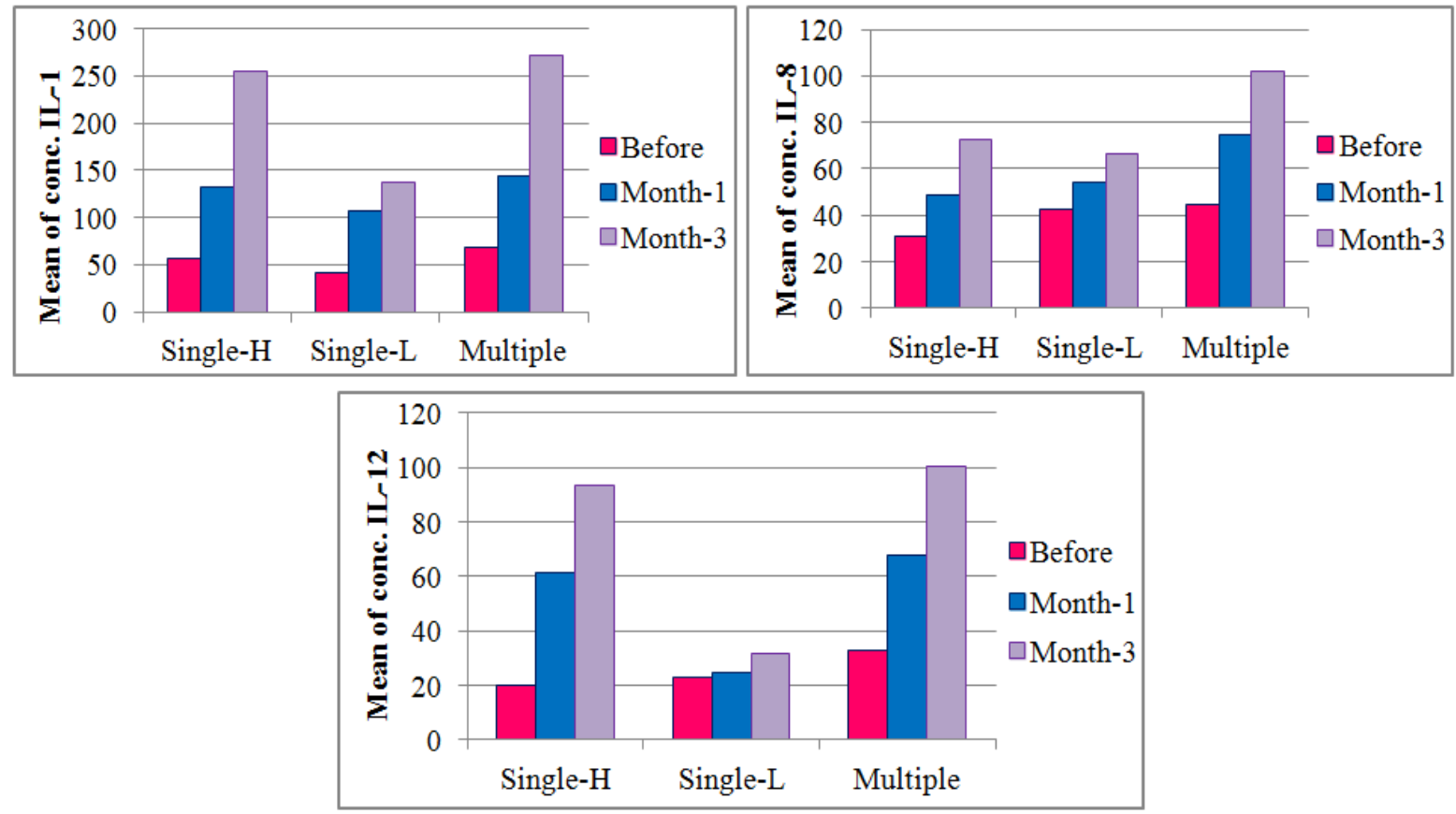

Figure 3. Observation of infection types with different cytokine levels in HPV infect women after on and three months of treatment with oral zinc sulfate, (a) for IL-1; (b) for IL-8 and (c) IL-12 level. 
Some investigators have reported that cell-mediated immunity (CMI) responses are associated with regression of disease whether single or multiple HPV types, others have found that CMI responses were associated with persistence of disease and high-grade dysplasia but were found infrequently in normal women [19]. Our finding emphasized that oral zinc sulfate plays an important role in highly significant production $(\mathrm{P}<0.01)$ of IL-1 and IL-12 when compared with their values before treatment at two periods. Moreover, the significant correlation in an increase in IL-1 and IL-12 response occur after one $(r=0.7)$ and three months $(r=0.8)$ of zinc treatment $(\mathrm{P}<0.01)$.

\section{Conclusion}

In conclusion, the IL-1 and IL-12 secretion are the most effects with zinc treatment at over three months to improve mild HPV infection with good hygiene.

\section{References}

[1]. M.A. Stanley. Immune response to human papillomaviruses. Indian J Med Research, 130, 2009, $266-276$.

[2]. S.M. Huang and McCance D.J. Down regulation of the interleukin-8 promoter by human papillomavirus type 16 E6 and E7 through effects on CREB binding protein/p300 and P/CAF. J Virol, 76, 2002, 8710-8721.

[3]. M. Indrova, Bieblova J., Rossowska J., Kuropka P., Pajtasz E., Bubenik J. and Reinis M. HPV 16-associated tumors: IL-12 can repair the absence of cytotoxic and proliferative responses of tumors infiltrating cell after chemotherapy. Journal Infected Disease, 34(1), 2009, 173-179.

[4]. A.S. Prasad, Beck F.W.J, Bao B., Fitzgerald J.T., Snell D.C. and Steinberg J.D. Zinc supplementation decreases incidence of infections in the elderly: effect of zinc on generation of cytokines and oxidative stress. American Journal Clinical Nutrition, 85 , $2007,837-844$

[5]. D.K. Heyland, Jones N., Cvijanovich N.Z. and Wong H. Zinc supplementation in critically ill patients: a key pharmaconutrient. JPEN Journal Parenter Enteral Nutrition, 32, 2008, 509-19.

[6]. A.S. Prasad. Zinc mechanisms of host defense. Journal Nutrition, 137, 2007, 1345-1349.

[7]. N. Raza and Khan D.A. Zinc Deficiency in Patients with Persistent Viral Warts. Journal of the College of Physicians and Surgeons Pakistan, 20(2), 2010, 83-86.

[8]. D.S. Saleh, Fadhil, H.Y. and AL-Hamdani, F.G. Screening for high-risk Human Papillomavirus by real-time PCR and its association with cytological abnormalities of Pap smear in Baghdad. Inter J Microbiol Res., 4(9), 2012, 332-335.

[9]. H. Y. Fadhil, Saleh, D.S. and Al-Hamdani, F.G. Detection of Human Papillomavirus-21 genotypes in a sample of Iraqi women with cervical abnormalities and cancer. Canadian J.pure and applied sciences, 8(1), 2014, 2671-2676.

[10]. J.A. Lieberman, Moscicki A.B., Sumerel J.L, Ma Y. and Scott M.E. Determination of cytokine protein levels in cervical mucus samples from young women by a multiplex immunoassay method and assessment of correlates. Clinical Vaccine Immunol, 15(1), $2008,49-54$

[11]. A. Cottage, Dowen, S., Roberts I., Pett M., Coleman N. and Stanley M., Early genetic events in HPV immortalised keratinocytes Genes Chromosomes Cancer., 30 (1), 2001, 72-79.

[12]. T. Liu, Soong S.J., Alvarez R.D. and Butterworth C.E., A longitudinal analysis of human papillomavirus 16 infection, nutritional status, and cervical dysplasia progression. Cancer Epidemiology Biomarkers Preview, 4 (4), 1995, 373-380.

[13]. S.G. Novick, Godfrey JC, Godfrey NJ and Wilder HR. How does zinc modify the common cold? Clinical observations and implications regarding mechanisms of action. Medical Hypotheses, 46, 1977, 295-302.

[14]. F.T. Al-Gurari, Al-Waiz M. and Sharque K.E. Oral zinc sulphate in the treatment of recalcitrant viral warts: randomized placebo controlled clinical trial. British J Dermatol, 146, 2002, 423-31.

[15]. I. Hassan, Bhat T., Altaf H., Sameem F. and Masood Q. Role of oral zinc sulphate in warts-aplacebo controlled, single-blinded study. Our Dermatology Online, 4 (1), 2013, 24-27.

[16]. M. Dardenne, Zinc and immune function. European Journal of Clinical Nutrition., 56 (Suppl 3), 2002 , S20-S23.

[17]. A.V. Ramanakumar, Goncalves O., Richardson H., Tellier P. and Franco E.L., HPV types 16,18,31,45 DNA loads and HPV-16 integration in persistent and transient infection in young women. BMC Infectious Disease, 10, 2010, 326-337.

[18]. S. Daayana, Elkord E., Winters U., Pawlita M., Roden R., Stern P. and Kitchener H.C., Phase II trial of imiquimod and HPV therapeutic vaccination in patients with vulval intraepithelial neoplasia. British Journal Cancer, 102, 2010, 1129-1136.

[19]. A. Kadish, Timmins P. and Wang Y. Regression of Cervical intraepithelial Neoplasia and loss of Human papillomavirus (HPV) infection is associated with Cell-mediated immune responses to an HPV type 16 E7 peptide. Cancer Epidemiology Biomarkers Preview, 11, 2002, 483-488. 